\title{
The Onlife Manifesto: Philosophical Backgrounds, Media Usages, and the Futures of Democracy and Equality
}

\author{
Charles Ess
}

\section{Introduction}

I begin by discussing three challenges we take to define our Onlife context. I first show how these challenges have been prefigured and addressed in prior philosophical developments, including phenomenology, virtue ethics, Kantian ethics, and others. This discussion then introduces us to the primary features of and contrasts between: the more individual sense of rational-autonomous selfhood characteristic of high modern Western thought, and; more relational senses of selfhood in both historical and contemporary contexts and theories (Bakardjieva 2005).

These two notions of selfhood are further illuminated by considerations of embodiment and developments in contemporary philosophy and Internet Studies. This brings us to the core point: the shift from more individual towards more relational selves in contemporary "Western" societies, as manifest first of all in our changing practices and theories of "privacy," risks a shift towards more hierarchical social structures and non-democratic polities - and thereby away from high modern democratic processes and norms, including equality and gender equality (Bakardjieva 2009) .

I then examine how far democratic processes and norms can be nonetheless preserved Onlife, drawing on notions of hybrid selves, "partial privacy" and "contextual privacy" (Nissenbaum 2010) and "subactivism” (Bakardjieva 2009). By contrast, emerging Confucian democracies, as resting on strongly relational conceptions of selfhood, appear to directly threaten commitments to equality and gender equality.

These theoretical and empirical findings highlight the urgency of our contemporary choices regarding media usages. Specifically, where writing and the skills of literacy-print (as the communication modality of high modernity, in contrast with the secondary orality of electric media in general and online communication in particular) are historically correlated with high modern notions of individual

\footnotetext{
C. Ess $(\bowtie)$

Department of Media and Communication, University of Oslo, Oslo, Norway

e-mail: c.m.ess@media.uio.no
} 
autonomy, democracy, and equality - I plea for continued emphasis on writing as "a technology of the self" (Foucault 1988) for the sake of sustaining democracy and equality (Baron 2008).

\section{The Relational Self and the Onlife Initiative: Descartes, Phenomenology, and the Analogue-Digital Age}

This section shows how three of the four challenges we highlight in the Onlife Manifesto - beginning with the blurring of the distinction between reality and virtuality - have been explored, grounded, and prefigured in modern philosophy, most especially phenomenology. The material in this section thus provides important historical context and philosophical groundings for the analyses and claims of the Onlife Manifesto.

Our background paper underlined four challenges to received frameworks evoked by the digital transition:

a. By blurring the distinction between reality and virtuality;

b. By blurring the distinctions between human, machine and nature;

c. By reversing from scarcity to abundance, when it comes to information;

d. By shifting from the primacy of entities over interactions to the primacy of interactions over entities. (Broadbent et al. 2013, p. 30)

Three of these have been explored, grounded and prefigured in modern philosophy, most especially phenomenology. A brief look at how this is so may be helpful for adding both additional historical context and philosophical substance to our shared understanding.

To do so, I offer in the following

(2.1) A brief summary of how Cartesian dualism underlies especially the hard distinction between the real and the virtual in the 1990s, and the several ways in which late 1990s work in several domains, including neuroscience, shift from Cartesian dualism;

(2.2) Some notes on significant developments in phenomenology that prefigure and ground such non-dualistic accounts, focusing on the work of Maurice Natanson (1970) as an example, followed by brief comments on more recent philosophers who extend phenomenological analyses and directly couple these with contemporary neuroscience;

(2.3) Summary comments that link these phenomenological backgrounds and insights to our guiding notions of "onlife" as first of all articulating just the refutation of the Cartesian1990 s' dualism between the real and the virtual, followed by

(2.4) Pointers to how these developments likewise prefigure and support especially "b" and "d" in our list.

\subsection{From Norbert Wiener to Enactivism and the Embedded Mind}

We first need to recall that the hard distinctions between the real and the virtual, as mapped onto equally hard distinctions between the offline and the online, especially unfolded in the relevant literatures on virtuality, virtual worlds, etc. In the 1990s, 
as can be seen in numerous sources, these distinctions squarely rest on a Cartesian dualism - one that radically divorces a non-cognitive body (and with it, the whole of nature as "extended substance") from a non-extended and thereby fully disembodied mind. As but one example: Katherine Hayles (1999, p. 288) discerned this dualism at work in the foundational discipline of cybernetics as developed by Norbert Wiener (1950). More broadly, this dualism reiterates ancient Gnostic and Greek dualisms that in turn root the Western Orthodox teaching of Original Sin-whose Augustinian language is in fact explicitly invoked in one of the key documents of early conceptions of cyberspace, namely, William Gibson's Neuromancer-the science-fiction novel that propelled the term 'cyberspace' into popular culture and academic discourse (Ess 2012b, pp. 5-7). Correlative notions of a disembodied "liberation in cyberspace" appealed both to "cyber-libertarians" such as John Perry Barlow (1996) as well as to some feminists and others rightly interested in overcoming the objectification and correlative subordination and violation of women (and others). Other feminists, however, early on raised warnings against the "old Cartesian trick" of seeking to forget the body (Stone 1991). Finally, by the end of the 1990s, this dualism was increasingly refuted along a range of research and reflection, including the work of Katherine Hayles, as well as that of Pierre Lévy (1998).

At the same time, the Cartesian-inspired epistemological models underlying much of the work in Artificial Intelligence in the latter half of the twentieth century - crudely, lumped under the name of cognitivism - were likewise receding in the face of emerging evidence in the neurosciences that highlighted the inextricable interactions between the various mechanisms and processes of "the body" and those traditionally affiliated with consciousness and awareness. These newer, radically non-dualistic views are captured under notions of "embedded mind," "embedded cognition," and "enactivism" (e.g., Horst 2011).

\subsection{Phenomenology}

From a historical perspective, however, these non-dualistic views are prefigured and developed within the frameworks of twentieth and twenty-first century phenomenology. Phenomenology can be briefly summarized as "the study of structures of consciousness as experienced from the first-person point of view" (Smith 2011). For example, by 1970, Maurice Natanson, drawing on the earlier work of Edmund Husserl, Jean-Paul Sartre, and Alfred Schutz, articulates a phenomenological account of the self as inextricably engaged with the world moment-to-moment. First of all, phenomenologists claim, we never experience "consciousness" as such, as abstract - but always as a concrete and specific consciousness of (X). Natanson writes: "To be conscious is to be conscious of something, a something which then stands to the activity of consciousness as the meaning of its performance" (1970, p. 3). Such consciousness, moreover, is that of a unitary self: "In the midst of action, the choices we make and the results of our choosing are to be understood in unitary fashion, as involving a being for whom the perception, evaluation, and definition of the situation are aspects of an integral self, a being at the center and source of a 
world" (1970, p. 3). In this way, experiential consciousness is always relationalwhether vis-à-vis its own self as made into an "object" of reflection and/or any further contents of consciousness, including other human beings and the world at large. For Natanson, this relationality is captured precisely in the erotic as the exemplar of fully engaged — and fully embodied — interrelationship:

[the self is] a being whose presence in the world is a unitary reality in which self and object are taken as integrally grounded in consciousness, understood as a directional force sustaining the entire range of perceptual life. Individual and action, self and situation, person and world are then bound to each other not only in their implications for each other but in their fundamental structure. Man [sic] is "in" the world as the lover is in relationship to the one he loves, not as the bearings are "in" the motor. (1970, p. 4)

In contrast, then, with an abstract, more or less universal self and body as located in an objective but external (Cartesian) grid of time and space - phenomenologically, we constantly experience ourselves as a unique "I," one who experiences the world around us from our unique, first-person standpoint. Natanson contrasts "objective" notions of time and space with our experiences of always being in a particular Here and Now - one defined by our distinctive standpoints as rooted in our individual bodies. In particular, Natanson uses the term "corporeality" to refer to our firstperson experiences of ourselves as a distinctive embodied self:

I am neither "in" my body nor "attached to" it; it does not belong to me or go along with me. I am my body. There is no distance between my hand and its grasping. [....] Instead of the common-sense way of thinking of the body in space at some time, I am a corporeality Here and Now whose being in the world is disclosed to me as mine. (1970, p. 11)

Natanson points out that these efforts at description are difficult to undertake, difficult to articulate, and difficult to take up in part because of three centuries of Cartesian philosophy that, contrary to phenomenological approaches, insists that "man can be understood in qualitatively the same terms as all other objects and events in the natural order. (1970, p. 4). This is to say: phenomenology resolutely resists the subordination of human beings, our experiences, and our self-understandings to the early modernist polarities of "subjective" vs. "objective" knowledge. Rather, phenomenology shares with existentialism the insistence on the epistemological legitimacy of first-person experience, contra its denigration as "mere subjectivity" in early modernity.

This phenomenological refutation of Cartesian mind-body dualism is further elaborated in the work of Merleau-Ponty, which inspired, for example, the neologism developed by the German philosopher Barbara Becker, Leibsubjekt- "Bodysubject" (2001). More recently, Susan Stuart has likewise built on the work of Merleau-Ponty (and others) in her conjunction of enactivism with phenomenology. Enactivism foregrounds how "... through a sensori-affective, felt dynamics, we build up non-conscious intentional expectations about how our world will continue to be" (2008, p. 256). Stuart sees this view of embodied cognition as directly meshing with phenomenological accounts of our experiencing the world as embodied knowersand-agents. Specifically, the embodied agent portrayed in enactivism is "essentially 
anti-dualistic" as this agent is "... dynamically-coupled to the world in which she is embedded; thus, agent, world and action are necessarily intricately interwoven, and the agent's body, experience, action, and world shape the way in which she deals with her everyday pragmatic concerns" (2008, p. 256).

Stuart goes on to explore possible linkages between the contemporary findings of enactivism and Kantian epistemology. I and May Thorseth have drawn on Stuart's work (among others) as highlighting these linkages between non-dualistic views of cognition and selfhood in the philosophical anthropology we have developed in our work on trust and virtual worlds, for example (Ess and Thorseth 2012, p. xviii ff.).

\subsection{Summary}

These phenomenological analyses emphasize radically non-dualistic and strongly relational notions of selfhood and embodiment in our knowing and navigating the world. They thereby prefigure and complement the similar turns we have seen in the late twentieth century, including the literatures of virtuality and virtual worlds (Lévy 1998), Internet studies more broadly, and emerging neuroscientific views of enactivism and the embodied mind.

\subsection{How These Developments Prefigure and Support Our Characterizations}

I hope it is now fairly straightforward to see how phenomenology directly supports our first characterization of life in the (analogue-) digital age, beginning with:

a. By blurring the distinction between reality and virtuality;

Again, in the 1990s this distinction mapped hard distinctions between the offline and the online, between what Barlow, drawing on Gibson, characterized as "meatspace" vs. Cyberspace - distinctions, finally, that rested on squarely Cartesian (if not Augustinian, Stoic, and Gnostic) dualisms. The dissolution of these dualismsin enactivism, feminism, and most especially phenomenology in the twentieth century - thus means the dissolution of a hard reality/virtuality distinction as well. In particular, Barbara Becker's neologism Leibsubjekt_"body-subject"1 — neatly anticipates and reinforces our defining neologism of "onlife" as a primary way of capturing these dissolutions.

\footnotetext{
${ }^{1}$ Leibsubjekt conjoins Leib (body) and subjekt (subject), where the latter refers to the full spectrum of facilities and actions we ordinarily associate with "subjectivity," including consciousness and self-consciousness, identity and self-identity, intentionality, affectivity, agency, and so on. Becker developed the term in conjunction with her larger critique of dualism and radical versions of social constructivism, in order to reassert the intransigent materiality of body, precisely as inextricably interwoven with our subjectivity. In this, she drew from phenomenology and from her own first-hand struggles with cancer. (Most sadly, the cancer ultimately took her life in 2009.)
} 
These developments directly support two of the remaining characterizations, namely,

b. By blurring the distinctions between human, machine and nature;

And

c. By shifting from the primacy of entities over interactions to the primacy of interactions over entities

With regard to " $b$ ": it would be helpful to recall and summarize here the extensive phenomenological analyses of how human beings experience the various tools we develop and use - most famously, beginning with Heidegger's concept of "readiness-to-hand". For us, the point is just that in our experiences of using our tools in engaged and familiar ways-in Heidegger's example, a carpenter using a hammerwe do not experience them as alien objects radically separate from our subjectivity. Rather, "there are no subjects and no objects; there is only the experience of the ongoing task (e.g., hammering)" (Wheeler 2011).

So far as I can gather, this thread of phenomenological analysis further meshes with more contemporary views of "embedded and embodied cognition." Steven Horst puts it this way:

Perception, action, and even imagination and reasoning are "embodied", not only in the sense of being realized through some physical system, but in the stronger sense that they involve bodily processes that extend beyond the brain into the nervous system and even into other tissue and to biochemical processes in the body. At the same time, even the brain processes involved in cognition involve non-representational, non-computational skills of bodily know-how. The mind is also "embedded" in its environment, not only in the sense of interacting with it causally through perceptual "inputs" and behavioral "outputs", but in the more radical sense that things outside the physical organism - from tools to prostheses to books and websites - are integrally part of cognition itself. We are, as Andy Clark puts it, already "natural-born cyborgs." (Horst 2011)

The cyborg - "cybernetic organism"- figure here is important. At least some early imaginings of cyborgs expressed precisely the great fear that such beings ostensibly represented the breakdown and violation of a strong nature-machine dichotomy. At least by the time of Donna Haraway's famous "Cyborg Manifesto" (1991), however, feminist thought rejected such fears as thereby resting on a (yet another) mistaken binary (cf. Lennon 2010).

Finally, these phenomenological and enactivist insights are likewise at work in the Medium Theory I draw on, beginning with Marshall McLuhan's defining principle in Understanding Media. Most simply, we create our technologies, including our communication technologies, as tools that extend ourselves in various ways: but our use of those tools reshapes us in turn. So he says, for example, "Physiologically, man in the normal use of technology (or his variously extended body) is perpetually modified by it and in turn finds ever new ways of modifying his technology" (1964, p. 46). As Richard Cavell has documented, McLuhan developed this understanding of technology, including communication qua technology, precisely within a foundational embrace of the body and correlative rejection of Cartesian dualism (2003, pp. 83-85). With regard to " $c$ ": here again, the focus on relationality-over against, say, a kind of Hobbesian focus on the individual conceived on the model 
of a (crude) atomism - is thematic in phenomenology as well as other twentieth century currents of thought.

As but one example in phenomenology: in her analysis and descriptions of various forms of sexual experience, Sara Ruddick first of all critiques more dualistic understandings of sexuality-i.e. as something that occurs solely between "bodies" as somehow radically separated from their "owner's" sense of selfhood and identity (1975). Rather, a phenomenological account of our most intense experiences (such as experiences of playing sports) foregrounds how in such experiences, there is no felt mind-body dualism, but rather an immediate unity of self and body. Not all sexual experiences count (or need to count) for Ruddick as involving such direct unity: but she argues that those that do are morally preferable first of all because in such experiences, our own personhood and autonomy cannot be separated from our bodies, and hence these experiences foster the Kantian duty of respect for the Other as a person. Ruddick further argues that such sexual experiences thereby foster two additional virtues-namely, the norm of equality and the virtue of loving (Ruddick 1975, p. 98 ff.; cf. Ess 2014). To recall Natanson, finally, our erotic engagement with an Other is at once the exemplar and a primary instantiation of our inextricable relationality with one another as co-constituting our identities as embodied beings (1970, p. 47 f.).

At the same time, at least to some degree, this focus on interactions more than isolated entities is already at work in Kant's epistemology. Broadly, Kant makes clear that science, as resting on both mathematical and empirical foundations, thereby focuses on the law-like relationships (Verhältnisse) between entities. This becomes perhaps most prominent in his Critique of Judgment, with its focus on the sensus communis as an intersubjectively shared sense of aesthetic judgment (Thorseth 2012).

As yet another example: in his "theory of communicative action," Habermas develops a phenomenological notion of a "life-world," one "bounded by the totality of interpretations presupposed by the members as background knowledge" (1985, p. 13). Such a life-world, with its background of shared assumptions, is then the context for the communicative practices Habermas takes as paradigmatic of rationality. As characterized by his expositor, Thomas McCarthy, Habermas focuses on morality as intertwined with a socialized intuition that further brings into play the (equally Aristotelian) recognition that self-identity, as shaped by the society in which one finds oneself, "...is from the start interwoven with relations of mutual recognition" (1994, p. 47). This interdependence, moreover, “...brings with it a reciprocal vulnerability that calls for guarantees of mutual consideration to preserve both the integrity of individual persons and the web of interpersonal relations in which their identities are formed and maintained." (ibid)

The phrase "the web of interpersonal relations," finally, echoes and reinforces especially feminist emphases on ethical decision-making within "the web of relationships," beginning with the work of Carol Gilligan (1982). At the same time, as we will explore more fully below, one of the most significant contemporary philosophical theories of privacy - namely, Helen Nissenbaum's account of privacy as "contextual integrity" (2010) — rests precisely on such relational notions of 
selfhood: Nissenbaum draws on the account of human beings developed by James Rachels - one that begins (again) with an account of selfhood as inextricably interwoven with the specific roles and relationships we engage in (1975).

None of this is accidental for our project. As I have documented earlier, Luciano Floridi's information ontology, as he himself emphasizes, "draws on the emphasis on the interconnection between all things familiar from recent environmental and feminist philosophies - and, importantly, from such non-Western views as Buddhism and Confucian thought" (Ess 2009, p. 161). This is to say: Floridi's information ontology, among its many other virtues, brings forward precisely the ways in which computational technologies and computer networks facilitate and enable our sense of selfhood as relational beings first of all. But as it does so, it thereby reiterates at least parallel understandings of selfhood qua relational found in both modern (Western) feminism, ecology, and phenomenology - if not in at least some version of Kant - as well as in both ancient Western and Eastern frameworks.

Insofar as this is true, then our focus in the (analogue-) digital age on interactions and relationality rightly highlights these as brought forward in striking new ways. But it may be more accurate to say that this is a renewed focus, one that has been brewing for quite some time in modern Western philosophy (if not in Kant, then certainly in phenomenology) — and one that would not seem unfamiliar to ancients in either Western or Eastern worlds.

\section{Digital-Analogue Media and the (re)Emergence of Relational Selves}

This section begins with a warning against our focusing overly much on "the digital" in our analyses, insofar as the analogue - most especially in the form of humans' embodied sensation and perception-does not disappear in the age of hyperconnected realities (3.1). Analogue embodiment further correlates with a stubborn insistence in contemporary philosophy and Internet Studies on singular identities (3.2). At the same time, there is strong evidence suggesting foundational shifts towards more relational and affective emphases of selfhood and identity in Western societies - along with correlative changes in our understandings and expectations of "privacy" (3.3). These shifts have enormous political consequences: most simply, where the individual-rational emphases of Western (high) modernity correlate with liberal-democratic institutions and core norms such as equality - historically, relational (and more affective) emphases have correlated with less egalitarian and more authoritarian forms of power and control (3.4).

\subsection{Digital Media and Digital Futures?}

A developing European "onlife" implicates at least two digitally-based technologies. The first (a) includes the multiple forms of (analogue-) digital media, where 
'media' refers to both (i) familiar technologies such as digital cameras and similar recording/storing technologies, often as embedded in smartphones, for the production and distribution of diverse forms of media qua content, as this content is (ii) distributed through (analogue-) digital media qua channels (computers and computer networks, but also more "traditional" radio and TV broadcasts, film, print, etc.) and devices (including "mobile-locative" devices such as smartphones, tablets, and other portable devices that are both connected to the Internet/Web and are GPSenabled). In these directions, the "mobility revolution" (better, in my view, "evolution') is a primary locus of the sorts of developments that we may anticipate to be central to the further evolution of onlife.

I think it increasingly critical to notice, however, that these technologies remain analogue technologies, beginning with their inputs (voice, light, etc.) and outputs (sound, image, etc.). This is important for two reasons: (a) just as we rightly concern ourselves with the affordances of digital technologies qua digital — so we need to attend to the affordances of the analogue components of these technologies as well, or otherwise risk a potentially misleading myopia in our focus, and (b) highlighting the analogue side of these technologies thereby highlights the embodied character of their designers, consumers, and users - -i.e., as human beings whose sensory and enkinaesthetic engagement with the world remains deeply analogue (cf. Massumi 2002). (As various schemes of human enhancement and re-engineering are realized, all of this may well change.)

(Analogue-) digital media are at work in other aspects of contemporary and future onlife, including (b) the development of "social robots" such as "telenoids." A telenoid is designed to convey embodied forms of communication, including "hugs" - while being remotely controlled through Internet and other forms of digital connections. Robots in various forms - including "care-bots," "warrior-bots," and, of course, "sex-bots"-will become increasingly commonplace appliances in an analogue-digital future, for better and for worse (Turkle 2011).

\subsection{Trust, Identity, and Polity}

A synthesis of philosophical approaches to trust has issued in a philosophical anthropology that highlights the role of embodiment in our knowing and navigating the world, including a phenomenologically-rooted emphasis on the Husserlian "I" or first-person perspective (indexicality) as anchoring our sense of experience in the world (Ess and Thorseth 2012). There emerges here a stubborn insistence on singular identity as rooted in the body, as well as in a Kantian epistemology that foregrounds the role of a transcendental unity of apperception in the construction of a coherent experience out of the otherwise fragmented and incoherent data stream-a unity expressed in the phrase and epistemological requirement of the "I think." More recent work in philosophy on "personal identity online" has reinforced these

\footnotetext{
${ }^{2}$ E.g., <http://spectrum.iee.org/automaton/robotics/humanoids/telenoid-r1-hiroshi-ishiguronewest-and-strangest-android $>$. Telenoids have been used in a pilot project on eldercare in Denmark, for example, with promising initial results.
} 
conceptions of identity, specifically with regard to online communicative engagements (Ess 2012a). A broad range of empirical findings from Internet Studies over the past decade or so likewise highlights the primacy of a singular identity - one that spans precisely the increasingly blurred distinction between online and offline, as our phrase "Onlife" suggests (Ess and Consalvo 2011; Ess and Dutton 2013).

\subsection{Changing Selves, Changing Privacies}

On the other hand, the particular emphases defining such selves and identities appear to be in flux. In "Western" societies, the affordances of what McLuhan and others call "electric media," including contemporary ICTs, appear to foster a shift from the modern Western emphases on the self as primarily rational, individual, and thereby an ethically autonomous moral agent towards greater (and classically "Eastern" and pre-modern) emphases on the self as primarily emotive, and relational -i.e., as constituted exclusively in terms of one's multiple relationships, beginning with the family and extending through the larger society and (super)natural orders. This can be seen in the first instance in the movement, especially among the young, from strongly individual notions of privacy towards "publicly private/ privately public" sharing of information on social networking sites (Facebook et al.) as well as in illegal sharing of copyrighted materials. These moves are followed by correlative shifts in privacy and copyright laws, i.e., away from laws built around earlier media and strongly individual and exclusive senses of privacy and property.

So, for example, Helen Nissenbaum builds her account of privacy as "contextual integrity" on the clearly relational sense of selfhood articulated by James Rachels, as we have seen. This account is further coherent with the language and conceptualizations of "privacy" in Denmark and Norway, for example. To be sure, strongly individual rights to privacy are protected here - in part, as these countries hold closely to European Union regulations of individual data privacy protection. At the same time, however, "privacy" is discussed here more in terms of privatlivet ("private life") and the intimsfcere ("intimate sphere"). These are understood in both individual and relational terms. In particular, Norway's research ethics guidelines make explicit the requirement that researchers not only to protect the privacy of individual subjects, but also that of their close relationships, i.e., those who constitute the individual's intimate sphere and private life (NESH 2006; Ess and Fossheim 2013). Similar comments hold with regard to property notions. The political program of the Pirate Party, for example, criticizes current intellectual property rights regimes as too individual and too exclusive, and thereby, as no longer suitable to contemporary attitudes towards and practices of sharing digital files - most notably, entertainment materials such as music and movies (Ess 2013, p. 92).

Par contra, in especially North Asian societies, the shifts go in the opposite direction - namely from strongly relational emphases in selfhood and identity towards increasingly individual emphases (Yan 2010; Hansen and Svarverud 2010). These shifts are reflected not only in radical changes in social practices, such as 
younger people demanding individual privacy (Japan, Thailand) as well as "privacy" shifting from an originally negative concept to a more Western concept of privacy as a positive good (China): they are further reflected in changing privacy laws, including the encoding of individual privacy rights in the Chinese constitution in recent years - so much so, in fact, as to include discussions of introducing due process rights (Sui 2011; Greenleaf 2011). (And this after a decade of the loss of due process rights in the U.S. and the E.U.: Cohen 2012.)

\subsection{Changing Selves, Changing Polities?}

Given the foundational importance of the rational-autonomous individual to not only classical conceptions of privacy, but also to modern Western conceptions of liberal democracies, these shifts are of enormous political moment as well. Specifically, as highlighted again in Medium Theory, classically relational selves correlate with hierarchical social structures and non-democratic regimes.

Given important caveats, ${ }^{3}$ a key question is how far these correlations will reappear-perhaps in the hybridized forms suggested by Walter Ong's (1988) notion of the "secondary orality" of electric media (i.e., one that hybridizes primary orality with subsequent communication modalities of literacy and print — where these last two correlate with the rise of the modern rational individual and liberal-democratic governance)? On the one hand, "Eastern" movement (at least in North Asia, along with, perhaps, analogous movements in the Islamic world, as manifest most dramatically in the "Arab Springs" of 2011) appears to indeed be towards more democratic forms of governance, as correlates of more rational-individual-autonomous conceptions of self and stronger individual conceptions of privacy. On the other hand, "Western" movement towards more relational (and emotive) emphases of selfhood correlate with, e.g., the erosion of due process rights for privacy, as well as increasing economic and political hierarchies in Western societies.

These developments may point towards a convergence between "Western" and "Eastern" societies of basic assumptions regarding identity and selfhood. This convergence may appear, for example, in recently developed notions of relational autonomy (Mackenzie 2008) and what Luciano Floridi has circumscribed as distributed morality and distributed responsibility (2012). These notions further overlap with our Onlife colleague Judith Simon's work on "Distributed epistemic responsibility," included here. All of this taken together represents important new developments in our understanding of what moral agency and responsibility might look like for selfhood and identity that conjoins both rational-individual and relationalaffective emphases - and where the relationality in play here includes the multiple relationships shared and embodied in the online networks that constitute much of our hyperconnected reality.

\footnotetext{
${ }^{3}$ Our Onlife colleague Mireille Hildebrandt has generously shared a wealth of relevant references that offer careful refinement and important revision regarding how we best characterize power relations in non-state societies.
} 
Ideally, such hybrid individual-relational selves will be able to sustain the democratic processes and norms - including equality - that correlate with modern emphases on rational-individual selves as cultivated through the communication technologies of literacy and print. But the rise of the relational self and shifts away from individual notions of privacy necessarily evokes a critical question: how far may equality and democratic processes survive in future societies as constituted by increasingly relational selves?

\section{Relational Selves, Democracy and Equality?}

I explore this question initially by way of a review of recent work in (Western) Internet Studies that highlights different expressions of "third spaces" of shared communication in online venues - i.e., ones that presume a sense of group rather than individual privacy. At the same time, these third spaces sustain individual privacy in significant ways, and thereby facilitate at least local or micro-level forms of political activism and democratizing citizenship (4.1). This work brings to the foreground, however, a core tension between modern Western commitments to the values of equality, including gender equality, and the values of more relational selves in late modern societies (4.2). Finally, (4.3) recent work on Confucian traditions helps both: reiterate this core tension between these traditions (as rooted in relational conceptions of selfhood) and Western commitments to robustly democratic regimes and a core modern value of equality, including gender equality (rooted in more individual conceptions of selfhood), and thereby; point towards what "democracy" might look like for more relational (and, perhaps, more emotive) selvesboth in praxis in contemporary North Asia and thereby as a concrete example of what "democracy 2.0" might look like in Western contexts as well.

\subsection{Recent Work in (Western) Internet Studies}

There is something of a thread of recognition in Internet Studies that online communication venues foster what might be called "third spaces," i.e., ones shaped by a sense of group sharing and intimacy that is neither individually private in a strong sense nor public in some wholesale sense. So, for example, Elizabeth Bassett and Kate O'Riordan described the interactions on a listserve devoted to GLBT participation and discussion in terms of a "partial privacy,"

... because the participants constructed utterances that they stated they would not convey to certain audiences such as their family. This facilitated the participant's illusion that Gaygirls.com was a space over which they exercised some control, and in which they could expect quite high levels of confidentiality, safety and freedom. (2002, p. 241)

This sense (however illusory) of a partially private communicative space characterizes manifold communicative phenomena in the age of Web 2.0 as well, for example, 
in Patricia Lange's account of how young people using Facebook are able to carve out "publicly private" and "privately public" communication strategies (2007). At the same time, such spaces closely cohere with Helen Nissenbaum's account of privacy as "contextual" (2010). Most briefly, Nissenbaum defines privacy in terms of a right to an "appropriate" flow of information, where this appropriateness in turn depends upon a specific context, such as the marketplace, education, political life, and so on. What is critical here is that this appropriateness is defined primarily by the expectations of the human agents whose specific roles and relationships constitute a given context. Following Nissenbaum's example: when two personsone as patient, the second as physician - thereby constitute a medical informational context, the patient expects certain norms of privacy regarding her medical details to be respected. On the one hand, these details are appropriately shared with other medical professionals immediately concerned with her case. On the other hand, the physician might instead operate by the informational norms of the marketplace, so as to put her details up for sale, e.g., to a drug or advertising company. While this more public use of her medical information might be perfectly appropriate within a marketplace context - within the medical context, the patient would rightly feel that her privacy expectations had been inappropriately violated (2010, p. 33).

Following Nissenbaum's account, it is hence perfectly appropriate for human agents, as engaging with one another across a range of possible relationships and roles, to establish and negotiate within specific contexts notions of "privacy" that are "partially public," i.e., as shared third spaces between a strictly individual conception of privacy and a fully public, non-private space. As we have seen, such conceptions are already in play and articulated in Denmark and Norway in the terms privatlivet and intimsfaere, and in the Norwegian research ethics guidelines. Even more concretely, Stine Lomborg has analyzed a prominent Danish blog (Huskebloggen, "The Memory Blog") as constituting an online example of the intimsfaere - a shared communicative space that is between strict individual privacy and wholesale publicity. Lomborg's analysis highlights fine-grained details of "phatic communication" between the primary blogger and her audience, communication that signals, "listenership, reciprocity, availability for conversation, concern and empathy, and this, in turn, frames the blog as a personal space" (2012, p. 428). Specifically,

To maintain the blog as a personal space, self-disclosure plays an important role through the personal, even intimate, experiences and emotions revealed in the blog conversation. By this means, both author and readers balance a fine line between, on the one hand, pressure to reveal personal issues as a preamble for developing relationships among participants and, on the other hand, a norm of non-intrusiveness to protect each other's [individual] privacy. (2012, p. 432)

The upshot, finally, is a sense of shared personal or intimate space that correlates with Georg Simmel's account of "the sociable self"- a self engaged in a network of relationships, where sociability means "highlighting similarities and de-emphasizing individuality in conversation by 'hiding' intimate and potentially uncomfortable topics because serious discussion disturbs and threatens the continuity of conversation." (ibid). 
This capacity to retain some element of individual privacy while participating in a shared intimate or personal space with others correlates with what we have seen above as the construction of a "public privacy" in online venues, as a third space between purely individual privacy and indiscriminant publicity. Moreover-and as we would expect in light of the historical and philosophical correlations between individual privacy and agency, on the one hand, and democratic processes on the other-this third space opens up distinctive political possibilities, as described by Maria Bakardjieva in terms of "subactivism" and "mundane citizenship" (2009). Bakardjieva acknowledges what we might think of as "the grand narratives" of conceptualizing the potentials of the Internet and the Web for helping to realize and expand democratic processes: these include communitarian and Habermasian frameworks that, from my perspective, tended to dominate discourse and research in the 1990s and in the early part of the twenty-first century. These grand versions of democracy, moreover, are often pitted against equally grand dystopian visionsperhaps most dramatically, the Orwellian "Big Brother" scenarios that "total transparency" online all but inevitably seems to entail (Jensen 2007). But Bakardjieva, prominent for her various explorations of "the Internet and everyday life" (2005), points to a more recent, somewhat more modest thread that runs squarely between these grand polarities:

A common feature of these works is the insistence that we should look for germs and projections of the political and public world in the private quarters and daily dealings of individual persons. Everyday thoughts, conversations, and activities have a bearing on democratic politics (see Couldry et al. 2007). Some of the necessary conditions for a functioning democracy exist at the level of lived experience, resources, and subjective dispositions (Dahlgren 2003). Put together, these arguments mark a "cultural turn" (Dahlgren 2003) in the study of democracy and political communication. (Bakardjieva 2009, p. 92)

Drawing on classical feminist sources as well as the work of Lefebvre (1971), Beck on "subpolitics" (1997), and Giddens" notion of "life politics" (1991) as foci more appropriate to a second stage or late modernity, Bakardjieva describes subactivism first in terms of its locus in

...the private sphere or the small social world. It blends ethics and politics, or oscillates around that fuzzy boundary where one merges into the other. It is rooted in the subject but necessarily involves collective identities often in an imagined form - recall Anderson's (1983) imagined communities. It is constituted by numerous acts of positioning — often in the imaginary vis-à-vis large-scale political, moral, and cultural confrontations, but also with respect to ongoing micro interactions and conversations. It is not about political power in the strict sense, but about personal empowerment seen as the power of the subject to be the person that they want to be in accordance with his or her reflexively chosen moral and political standards. (Bakardjieva 2009, p. 96; emphasis added, CE)

While grounded, we may say, in an everyday lifeworld not immediately focused on democracy in the larger, more prominent ways (e.g., the Arab Springs) - this subactivism nonetheless contains the potential for not insignificant political activity and impact:

Subactivism may or may not leak out of the small social world and become publicly visible, meaning that its acts and products, although multiple, can remain insulated in the private 
sphere. This, however, does not condemn subactivism to inconsequentiality. The potential for it to be mobilized by trigger events and transformed into overt public activism is always in place. It is that essential bedrock against which individual citizens' capacity for participation in subpolitics or in the formal political institutions of the public world is shaped and nurtured. (ibid)

In short, this conception of subactivism foregrounds the political possibilities that attach to a more "mundane citizenship," one primarily focusing on micro-level efforts as empowerment rooted in individual and small group interests. While not democracy on a grand (Habermasian or communitarian) scale-neither is this the complete loss of individual autonomy and democracy as threatened in more Orwellian visions. At the same time, the online communicative spaces that facilitate and foster such "subactivism" thereby share the same structures and characteristics of the third or "personal space" described by Lomborg, i.e., one that balances between a (still protected) individual privacy and an indiscriminate publicity. Such third spaces, again, are best described in terms of "partial privacy" (Bassett and O'Riordan 2002) and "contextual privacy" (Nissenbaum 2010). In particular, such spaces, as they allow individual participants to negotiate what they share for the sake of sociability and subactivism at the micro-level, thereby preserve a classic modern Western sense of individual privacy as protecting individual agency and autonomy - precisely for the sake of the project of being/becoming "the person we want to be" (Bakardjieva 2009, p. 96).

In broadest terms, this would mean that the relational or sociable selves of late modernity, while fully entangled in the communicative networks facilitated by Web 2.0 technologies, may indeed emerge as hybrid selves, ones that preserve at least some of the classic modern emphases on individual autonomy and agency-including the democratic correlates thereof, at least in local or small scales.

\subsection{Core Tension: Equality and Gender Equality}

At the same time, however, there is a key point of tension in the appeal to Giddens' account of "life politics" - in contrast with the "emancipatory politics" of classic Western modernity. As Pak Wong has characterized these:

\footnotetext{
... where the former seeks individual liberation from (pre-)existing constraints, and aims to "reduce or eliminate exploitation, inequality and oppression" by "the imperatives of justice, equality and participation" (Giddens 1991, p. 211 f.), the latter is "a politics of lifestyle" that concerns with the question of 'how shall we live?' (Wong 2012, p. 86)
}

Wong further ties emancipatory politics to Charles Taylor's account of the disengaged rational autonomous self as the sense of self emerging from the Enlightenment and fostering Western conceptions of democracy and the liberal state (Taylor 1989). Such a self is further marked by specific value commitments:

Values such as knowledge, autonomy and equality are being strived for to free people from any pre-given natural and social orders. These values are important because they are about people's life chances. Once people are liberated from these constraints, they are propelled 
to consider the questions concerning their self-actualization. As such, life politics represents an increasing emphasis on values such as authenticity, individuality and diversity. (Wong 2012, p. 86 f.)

The critical point here is: how far does the transition to late modernity —and, in our terms, the shift towards a more relational (and perhaps emotive) self as facilitated by "electric media" most broadly and digital media in particular - involve:

Either - an abandonment of the core values of emancipatory politics - including autonomy, equality, and gender equality - in a "life politics" that stresses different values, And/Or- "life politics" as presuming, building upon, and thereby always necessarily incorporating the core values - and conception of self — of emancipatory politics?

The force of this question can be illuminated by exploring it within contemporary Confucian philosophy and real-world political contexts-i.e., the People's Republic of China (PRC) and its governing Chinese Communist Party (CCP).

\subsection{Recent Work on Confucian Traditions and Contemporary Communication Technologies}

Most briefly, Wong's thesis presents an exceptionally fine-grained analysis of the shifts in conception of selfhood that are central here - in both Western and Eastern, specifically Confucian traditions. On the one hand, as we have just seen, Wong finds an open tension between the sense of self and core values of the emancipatory politics of classical Western modernity and those of the "life politics" characteristic of what is variously characterized as "late," "second stage," or "radicalized modernity".

In particular, after carefully reviewing a number of prominent critics and proponents of Web 2.0 technologies, Wong argues that the dividing line between critics and proponents in large measure rests precisely on their preferred conceptions of selfhood. Simply, the critics (including Nicolas Carr (2010), Sherry Turkle (2011), and Jaron Lanier (2010)) see contemporary media technologies as threatening either the modern disengaged (rational-autonomous) and/or expressive (Romantic) self as accounted for in Taylor's work. By contrast, the proponents (e.g., Clay Shirky 2009,2010 ) see these technologies as fostering precisely the more relational (and perhaps emotive) sense of self at work in "life politics" (Wong 2012, pp. 102-114). For Wong this remains an open debate - one that leaves us with some room (still) for choice in terms of what digital literacies, perhaps in conjunction with more classical literacies as rooted in literacy-print, we will take up, precisely in light of which sorts of social structures and political regimes we prefer, i.e., more egalitarian vs. More hierarchical, and more democratic vs. more non-democratic (2012, p. 123 f.).

Such a choice is clearly consistent with what we can call the third spaces of subactivism as a shorthand for the accounts of online communication and mundane citizenship in the work of Lomborg and Bakardjieva. Specifically, a choice in favor of sustaining equality and democracy would thereby favor the literacies and media 
usages that preserve individual autonomy and privacy of agents who at the same time participate in savvy ways in the construction of such third spaces.

When Wong turns to Confucian thought and the Chinese Internet (as explored both through CCP documents and official newspaper pronouncements), however, the tension between emancipatory politics and life politics becomes pronounced and irresoluble.

To begin with, Confucian thought is rooted in hierarchical and patriarchal family structures, stressing first of all the virtue of filial piety. This family model becomes the model for the larger society, issuing in a clearly hierarchical structure of a paternalistic (if not frankly authoritarian) regime responsible for the well-being of a clearly subordinate people whose primary virtues are keyed towards sustaining harmony (te) within the larger community (Wong 2012, pp. $141 \mathrm{ff}$.).

This means, in particular, that Confucian thought thereby foregrounds familial privacy vis-à-vis the larger society. This is in keeping with the sense-at least prior to the past few decades - in Japan, Thailand, and China, that individual privacy must be something negative. At the same time, we can see in this conception of Confucian familial or group privacy, as rooted in a relational conception of the self, a counterpart or analogue to the sorts of "partially private" third spaces described above as characteristic of contemporary Western usages of digital media technologies.

This analogy with contemporary Western contexts is further strengthened in terms of the sense of selfhood at work here. Wong describes a "bicultural" or dual sense of selfhood that has emerged in Confucian tradition since exposure to Western cultures - namely, that of a small self (akin to the Western notion of the individual pursuing individual interests and desires, etc.) vis-à-vis "the great self" as relational and thereby concerned first with the well-being of the country (Wong 2012, p. 167). But again, if there is conflict between the great self and the harmony of the larger community vs. the small self and its strictly individual interests, then the small self must capitulate. In the terms developed above, individual autonomy and privacy (of the small self), however it may be sustained in Western contexts in third spaces and subactivism, will be sacrificed for the greater good in a strongly Confucian context.

But this further means that within this Confucian context, fundamental equality - both individual equality and with it gender equality - is simply an untenable, if not frankly undesirable value. Wong points out that this point has been made in the work of Mary Bockover, who concludes that "Western values of free expression, equality and free trade as well as the idea of personal and political autonomy are incompatible with Confucian values" (2010, p. 170; cited in Wong 2012, p. 168). While Wong argues persuasively that some forms of free expression and free economic exchange might survive (or even thrive) within contemporary (and future) Confucian China - equality (between individuals and between genders) will always disappear in the general subordination of "the people" to the government, a subordination willingly practiced as a virtue of "the great self."

Both Wong's thesis and forthcoming publications offer very helpful accounts of emerging Confucian politics as compatible with the "third spaces" and "subactivism" we have explored. These accounts suggest that, insofar as Western 
developments may emerge in ways importantly analogous with North Asian Confucian (and Buddhist) traditions, we can be cautiously optimistic that some form of democratic processes and at least some characteristic democratic values may survive and thrive as digital media technologies continue to interact with our senses of selfhood, "life politics," etc.

However that may be, these and other considerations (e.g., the ways in which the "return of the body" in developing communication technologies brings in its train the return and reinforcement of gender stereotypes in our self-presentations online) suggest that the classical modern conception of the self as an individual autonomy, its democratic engagements, and specifically commitments to individual privacy and the values of equality and gender equality may well be imperiled in the transition from emancipatory politics to "life politics" of late modernity. That is, insofar as the latter - and its conception of the self as primarily relational (and, perhaps, more emotive than rational) - is no longer seen to be rooted in and dependent upon the former, but rather as fully replacing the former: then, as the contemporary Chinese Confucian examples make clear, equality and gender equality will be sacrificed - along with the individual or "small self" - for the sake of greater harmony in a forthrightly hierarchical society.

\section{Concluding Remarks}

This analysis of Confucian societies is intended first of all to indicate that hybrid selves may well retain some dimensions of individual selfhood alongside more relational ones - sufficient for sustaining some aspects of democratic processes and commitments, but not necessarily sufficient for sustaining high modern Western norms of equality, including gender equality.

None of this is meant to suggest that Confucian societies are to be judged as necessarily deficient for their lack (so far) of commitments to equality and gender equality norms. Given the analogy Confucian societies may offer for future democratic societies constituted by more relational selves - the point is rather to suggest that the shift towards more relational selfhood seems to put at risk high modern Western norms of equality and gender equality.

Insofar as this is true, Medium Theory would argue that we now stand at a unique place of choice in both "Eastern" and "Western" societies - namely, the choice of determining the relative weight or emphasis on the individual vis-à-vis relational aspects of selfhood and identity. Most simply: if we should choose to sustain strong democratic societies, including commitments to norms of equality and gender equality — such a choice would entail sustaining high levels of the skills and abilities affiliated with literacy-print.

That is, to recall Foucault (1988), writing in particular is a technology of a particular sort of self, namely, the sort of (more) individual-rational self of high modernity - the autonomous subject, agent, and thereby citizen requisite who both justifies and requires high modern Western liberal-democratic societies and their core norms 
of equality and gender equality. Our choices for future media use seem clear. If we do not want to risk equality norms and democratic processes, then we must endorse continued, if not expanded, emphasis on the acquisition and cultivation of the skills affiliated with literacy-print. Such cultivation need not come at the cost of diminishing attention to digital (electric) media skills. But to allow the latter to eclipse the former runs the very great risk, in my view, of society-wide losses of our abilities to cultivate the sorts of selves requisite for democracies and strong equalities.

Open Access This chapter is distributed under the terms of the Creative Commons Attribution Noncommercial License, which permits any noncommercial use, distribution, and reproduction in any medium, provided the original author(s) and source are credited.

\section{References}

Anderson, Benedict. 1983. Imagined communities: Reflections on the origin and spread of nationalism. London: Verso.

Bakardjieva, Maria. 2005. Internet society: The internet in everyday life. London: Sage.

Bakardjieva, Maria. 2009. Subactivism: Lifeworld and politics in the age of the internet. The Information Society 25:91-104.

Baron, Naomi. 2008. Always on: Language in an online and mobile world. Oxford: Oxford University Press.

Bassett, Elizabeth H., and Kathleen O'Riordan 2002. Ethics of Internet research: Contesting the human subjects research model. Ethics and Information Technology 4 (3): 233-247.

Beck, Ulrich. 1997. The reinvention of politics: Rethinking modernity in the global social order. Cambridge: Polity Press.

Becker, Barbara. 2001. The disappearance of materiality? In The multiple and the mutable subject, eds. V. Lemecha and R. Stone, 58-77. Winnipeg: St. Norbert Arts Centre.

Bockover, Mary I. 2010. Confucianism and ethics in the western philosophical tradition I: Foundational concepts. Philosophy Compass 5 (4): 307-316.

Broadbent, Stefana, Nicole Dewandre, Charles Ess, Luciano Floridi, Jean-Gabriel Ganascia, Mireille Hildebrandt, Yiannis Laouris, Claire Lobet-Maris, Sarah Oates, Ugo Pagallo, Judith Simon, May Thorseth, and Peter-Paul Verbeek. 2013. Background document: Rethinking public spaces in the digital transition, The Onlife Initiative, 26-34. Brussels: European Commission. https://ec.europa.eu/digital-agenda/sites/digital-agenda/files/Onlife_Initiative.pdf. Accessed 1 July 2013.

Carr, Nicholas. 2010. The shallows: What the internet is doing to our brains. New York: W.W. Norton.

Cavell, Richard. 2003. McLuhan in space: A cultural geography. Toronto: University of Toronto Press.

Cohen, Julie. 2012. Configuring the networked self: Law, code, and the play of everyday practice. New Haven: Yale University Press.

Couldry, Nick, Sonia Livingstone, and Terry Markham. 2007. Connection or disconnection? Tracking the mediated public sphere in everyday life. In Media and public spheres, ed. R. Butsch, 28-42. New York: Palgrave-Macmillan.

Dahlgren, Peter. 2003. Reconfiguring civic culture in the new media milieu. In Media and political style: Essays on representation and civic culture, eds. J. Corner and D. Pels, 151-170. London: Sage. 
Ess, Charles. 2009. Floridi's philosophy of information and information ethics: Current perspectives, future directions. The Information Society 25:159-168.

Ess, Charles. 2012a. At the intersections between internet studies and philosophy: "Who Am I Online?" Philosophy and Technology 25 (3, September): 275-284. doi:10.1007/s13347-0120085-4.

Ess, Charles. 2012b. Self, community, and ethics in digital mediatized worlds. In Trust and virtual worlds: Contemporary perspectives, eds. C. Ess and M. Thorseth, 3-30. Oxford: Peter Lang.

Ess, Charles. 2013. Digital media ethics. 2nd ed. Oxford: Polity Press.

Ess, Charles. 2014. Ethics at the boundaries of the virtual. In The Oxford handbook of virtuality, ed. Mark Grimshaw, 683-697. Oxford: OUP.

Ess, Charles, and Mia Consalvo. 2011. What is Internet Studies? In The handbook of internet studies, eds. M. Consalvo and C. Ess, 1-7. Oxford: Wiley-Blackwell.

Ess, Charles, and May Thorseth. 2012. Introduction. In Trust and virtual worlds: Contemporary perspectives, eds. C. Ess and M. Thorseth, vii-xxiv. New York: Peter Lang.

Ess, Charles, and William Dutton. 2013. Internet studies: Perspectives on a rapidly developing field. New Media and Society 15 (5): 633-643.

Ess, Charles, and Hallvard Fossheim. 2013. Personal data: Changing selves, changing privacies. In The digital enlightenment yearbook 2013: The value of personal data, eds. Mireille Hildebrandt, Kieron O'Hara, and Michael Waidner, 40-55. Amsterdam: IOS Amsterdam.

Floridi, Luciano. 2012. Distributed Morality in an information society. Science and Engineering Ethics. doi:10.1007/s11948-012-9413-4.

Foucault, Michel. 1988. Technologies of the self. In Technologies of the self: A seminar with Michel Foucault, eds. L. H. Martin, H. Gutman, and P. Hutton, 16-49. Amherst: Univ. Massachusetts Press.

Giddens, Anthony. 1991. Modernity and self-identity: Self and society in the late modern age. Stanford: Stanford University Press.

Gilligan, Carol. 1982. In a different voice: Psychological theory and women's development. Cambridge: Harvard University Press.

Greenleaf, Graham. 2011. Asia-Pacific data privacy: 2011, year of revolution? UNSW Law Research Paper No. 2011-29, 2011. http://papers.ssrn.com/sol3/papers.cfm?Abstract id=1914212. Accessed 1 July 2013.

Habermas, Jürgen. 1985. The theory of communicative action, vol. 1: Reason and the rationalization of society. Boston: Beacon Press.

Hansen, Mette Halskov, and Rune Svarverud, eds. 2010. The Rise of the individual in modern chinese society. Copenhagen: Nordic Institute of Asian Studies.

Haraway, Donna. 1999. A cyborg manifesto: Science, technology, and socialist-feminism in the late twentieth century. In Simians, cyborgs and women: The reinvention of nature, 149-181. New York: Routledge.

Hayles, Katherine. 1999. How we became posthuman: Virtual bodies in cybernetics, literature, and informatics. Chicago: University of Chicago Press.

Horst, Steven. 2011. The computational theory of mind. The Stanford encyclopedia of philosophy, Edward N. Zalta (ed.). http://plato.stanford.edu/archives/spr2011/entries/computational-mind/. Accessed 1 July 2013.

Jensen, Jakob Linaa. 2007. The internet omnopticon. In New publics with/out democracy, eds. H. Bang and A. Esmark, 351-380. Copenhagen: Samfundslitteratur.

Lange, Patricia G. 2007. Publicly private and privately public: Social networking on youtube. Journal of Computer-Mediated Communication, 13 (1), article 18. http://jcmc.indiana.edu/ vol13/issue1/lange.html. Accessed 1 July 2013.

Lanier, Jaron. 2010. You are not a gadget: A manifesto. London: Allen Lane.

Lefebvre, Henri. 1971. Everyday life in the modern world. New York: Harper \& Row.

Lennon, Kathleen. 2010. Feminist perspectives on the body. The Stanford encyclopedia of philosophy, Edward N. Zalta (ed.). http://plato.stanford.edu/archives/fall2010/entries/feministbody/. Accessed 1 July 2013.

Lévy, Pierre. 1998. Becoming virtual. New York: Basic Books. 
Lomborg, Stine. 2012. Negotiating privacy through phatic communication: A case study of the blogging self. Philosophy and Technology 25 (2012): 415-434.

Mackenzie, Catriona. 2008. Relational autonomy, normative authority and perfectionism. Journal of Social Philosophy 39 (4, Winter): 512-533.

Massumi, Brian. 2002. Parables for the virtual: Movement, affect, sensation. Durham: Duke University Press.

McCarthy, Thomas. 1994. Kantian Constructivism and Reconstructivism: Rawls and Habermas in Dialogue" Ethics 105 (October 1994): 44-63.

Natanson, maurice. 1970. The journeying self: A study in philosophy and social role. Reading: Addison-Wesley.

Nissenbaum, Helen. 2010. Privacy in context: Technology, policy, and the integrity of social life. Palo Alto: Stanford University Press.

Ong, Walter. 1988. Orality and literacy: The technologizing of the word. London: Routledge.

Rachels, James. 1975. Why privacy is important. Philosophy and Public Affairs 4 (4): 323-333.

Ruddick, Sara. 1975. Better sex. In Philosophy and sex, eds. R. Baker \& F. Elliston, 280-299. Amherst, NY: Prometheus Books.

Shirky, Clay. 2009. Here comes everybody: How change happens when people come together. London: Penguin.

Shirky, Clay. 2010. Cognitive surplus: Creativity and generosity in a connected age. London: Allen Lane.

Smith, David Woodruff. 2011. Phenomenology. The Stanford encyclopedia of philosophy, Edward N. Zalta (ed.). http://plato.stanford.edu/archives/fall2011/entries/phenomenology/. Accessed 1 July 2013.

Stone, Allucquere R. 1991. Will the real body please stand up? Boundary stories about virtual cultures. In Cyberspace: First steps, ed. M. Benedikt, 81-118. Cambridge: MIT Press.

Stuart, Susan. 2008. From agency to apperception: Through Kinaesthesia to cognition and creation. Ethics and Information Technology 10 (4): 255-264.

Sui, Suli. 2011. The law and regulation on privacy in China. Paper presented at the Rising Pan European and International Awareness of Biometrics and Security Ethics (RISE) conference, October 20-21, 2011. Beijing, China.

Taylor, Charles. 1989. Sources of the self: The making of modern identity. Cambridge: Cambridge University Press.

The [Norwegian] National Committee for Research Ethics in the Social Sciences and the Humanities (NESH). 2006. Forskningsetiske retningslinjer for samfunnsvitenskap, humaniora, juss og teologi [Research ethics guidelines for social sciences, the humanities, law and theology]. http://www.etikkom.no/Documents/Publikasjoner-som-PDF/Forskningsetiske $\% 20$ retningslinjer\%20for\%20samfunnsvitenskap, $\% 20$ humaniora, $\% 20$ juss $\% 20$ og $\% 20$ teologi $\% 20$ $\% 282006 \% 29$.pdf. Accessed 1 July 2013.

Thorseth, May. 2012. Virtuality and trust in broadened thinking online. In Trust and virtual worlds: Contemporary perspectives, eds. C. Ess and M. Thorseth, 162-171. Oxford: Peter Lang.

Turkle, Sherry. 2011. Alone together: Why we expect more from technology and less from each other. Boston: Basic Books.

Wheeler, Michael. 2011. Martin Heidegger. The Stanford encyclopedia of philosophy, Edward N. Zalta (ed.). http://plato.stanford.edu/archives/win2011/entries/heidegger/. Accessed 1 July 2013.

Wiener, Norbert. 1950. The human use of human beings: Cybernetics and society. Boston: Houghton Mifflin.

Wong, Pak. 2012. Net recommendation: Prudential Appraisals of digital media and the good life. Phd thesis, Department of Philosophy, University of Enschede, Enschede, The Netherlands.

Yan, Yunxiang. 2010. The Chinese path to individualization. The British. Journal of Sociology 61 (3): 489-512. 